\title{
UJI AKTIVITAS ANTIOKSIDAN DAN SIFAT ORGANOLEPTIK TEH HERBAL CAMPURAN DAGING BUAH PARE (MOMORDICA CHARANTIA L.) DAN KULIT BUAH NAGA MERAH (Hylocereus Lemairei (HOOK.) BRITTON \& ROSE)
}

\author{
Yulisma Sudarsi, Musyirna Rahmah Nst
}

\author{
Sekolah Tinggi Ilmu Farmasi Riau \\ e-mail:yulismasudarsi@gmail.com,musyirnarahmah@stifar-riau.ac.id
}

\section{ABSTRACT}

Herbal tea is a herbal mixture made from flowers, leaves, seeds and or roots of various plants. Some of herbal tea consumed for adds energizing, help relaxation, overcome digestive problems and also strengthen the immune system. Research on antioxidant activity and organoleptic characteristic mix flesh of bitter melon fruit (Momordica charantia L.) and red dragon fruit skin (Hylocereus lemairei (Hook.) britton \& rose) herbal tea has been done. The objective of this research was to make a herbal tea formulation that has a high antioxidant activity and is preferred from a mixture of bitter melon fruit and red dragon fruit skin that has been dried at $50-60^{\circ} \mathrm{C}$. The antioxidant activity were measured by free radical scavenging method with DPPH; whereas organoleptic test was measured by hedonik method. The results of 5 formulas indicate that antioxidant activity is the highest in FIII formula that has the most content of bitter melon fruit. Data were analyzed using one way ANOVA and Tukey method at $99 \%$ confidence level. The herbal tea formulation of a coarse powder mixture of $1.75 \mathrm{~g}$ of bitter melon fruit and a coarse powder of $0.25 \mathrm{~g}$ red dragon fruit showed the highest antioxidant activity with percent inhibition of 98,249\% and preferably with the likes after adding $30 \mathrm{~mL}$ of honey.

Keywords : Antioxidant, Bitter Melon Fruit (Momordica charantia L.), Red Dragon Fruit (Hylocereus lemairei (Hook.) britton \& rose), Herbal Tea, Organoleptic

1

\section{PENDAHULUAN}

Antioksidan dapat diperoleh dari tanaman berkhasiat obat, buah-buahan dan sayur-sayuran, diantaranya seperti famili Cactaceae dan famili Cucurbitaceae. Famili Cucurbitaceae yang sering dikonsumsi adalah buah pare (Momordica charantia L.). Pare merupakan tanaman berbuah pahit, tumbuh di daerah tropis, mudah dibudidayakan, dan tidak bergantung musim (Riyadi et al, 2015). Dibalik rasa pahit buah pare secara empiris berkhasiat untuk obat demam, disentri, batuk, kencing manis, dan radang tenggorokan (Wisam, 2007).

Beberapa penelitian telah dilakukan untuk mengetahui aktivitas famili Cucurbitaceae, seperti yang dilakukan oleh Islam et al (2011) diperoleh persen inhibisi pada pengujian aktivitas antioksidan pada ekstrak metanol dari empat varietas Momordica charantia L. berkisaran $79-88 \%$ pada konsentrasi 500 ppm untuk tiap ekstrak. Pada penelitian Hamissou et al (2013) dalam penelitiannya melaporkan adanya aktivitas antioksidan pada ekstrak air pare (Momordica charantia L.) sebesar 82,05\%.

Aktivitas antioksidan juga dilaporkan oleh Lestari (2016) dalam penelitiannya didapatkan aktivitas antioksidan dengan persen inhibisi $88,127 \%$ pada minuman herbal formulasi III dengan komposisi $10 \mathrm{~g}$ buah pare, 7,5 g kulit buah naga merah dan $30 \mathrm{~mL}$ madu. Minuman herbal ini dibuat dengan cara infusa menggunakan sampel segar sehingga kandungan senyawa yang diperoleh dalam keadaan segar. Namun, pembuatan minuman herbal ini memiliki kelemahan harus segera diminum karena dikhawatirkan akan terkontaminasi oleh 
mikroba bila disimpan lama tanpa pengawet selain itu tidak semua kalangan masyarakat dapat membuat infusa dengan cara yang benar sehingga khasiat dari senyawa dalam tanaman tidak dapat diperoleh secara sempurna.

Selain buah pare, buah naga juga menjadi salah satu tanaman obat yang kaya antioksidan. Buah naga adalah buah tanaman jenis kaktus dari famili Cactaceae (Emil, 2011). Buah naga yang populer di Indonesia memiliki dua varian, yaitu buah naga merah (Hylocereus lemairei (Hook.) Britton \& Rose) dan buah naga putih (Hylocereus undatus). Buah naga merah memiliki aktivitas antioksidan yang lebih tinggi dibanding buah naga putih (Choo, 2011). Hal ini dipengaruhi oleh kadar senyawa betasianin yang merupakan pigmen yang memberikan warna merah sampai ungu pada buah naga merah lebih besar dari pada buah naga putih (Shofiati, 2014).

Dalam penyajiannya, antioksidan dapat dikonsumsi dari sediaan herbal seperti teh. Teh herbal dapat dikonsumsi sebagai minuman sehat yang praktis tanpa mengganggu rutinitas sehari-hari dan tetap menjaga kesehatan tubuh. Selain itu teh herbal juga dapat menambah energi, membantu relaksasi tubuh, mengatasi masalah pencernaan dan meningkatkan sistem kekebalan tubuh (Ravikumar, 2014). Untuk mengonsumsi teh dengan takaran yang cukup, praktis serta memaksimalkan khasiat yang diperoleh dari teh herbal dapat dibuat dengan sediaan kemasan teh celup.

\section{METODOLOGI PENELITIAN}

\section{Alat dan Bahan}

Alat: Gunting, pisau, timbangan analitik (ABS 220-4 BALANCE $^{\circledR}$ ), oven, baskom, telenan, gelas beker (IWAKI PYREX $^{\circledR}$ ), tabung reaksi (IWAKI PYREX ${ }^{\circledR}$ ), gelas ukur (IWAKI PYREX ${ }^{\circledR}$ ), pipet tetes, spatel, pipet mikro (Dragon Lab ${ }^{\circledR}$ ), plat tetes, lampu bunsen, satu set alat Microplate reader 96 walls (BERTHOLD LB 941C) dan Moisture Analyzer (AND MX-50 ${ }^{\circledR}$ ), kapas, aluminium foil, kantong teh, tisu dan kertas label.

Bahan: Buah pare (Momordica charantia L.), kulit buah naga merah (Hylocereus lemairei (Hook.) Britton \& Rose), aquadest (BRATACO CHEMIKA®), madu, metanol, larutan DPPH $80 \mu \mathrm{g} / \mathrm{ml}$, kloroform, logam $\mathrm{Mg}$, asam klorida pekat, Besi (III) klorida, pereaksi Mayer, asam asetat anhidrat dan asam sulfat pekat.

\section{Cara Kerja}

\section{Pengambilan Sampel}

Sampel buah pare (Momordica charantia L.) diperoleh dari kebun Unit Percobaan Tanaman (UPT) Pertanian Universitas Riau. Buah naga merah (Hylocereus lemairei (Hook.) Britton \& Rose) diperoleh dari kebun buah naga merah di Jalan Pasir Putih, Pekanbaru.

\section{Pembuatan Simplia}

Buah yang telah dikumpulkan dibersihkan dari kotoran-kotoran yang menempel (sortasi basah), dicuci dengan air mengalir sampai bersih, kemudian tiriskan untuk membebaskan buah dari sisa-sisa air cucian. Buah pare yang telah bersih dan bebas dari sisa air cucian kemudian daging buah dipisahkan dari bijinya lalu dirajang tipis $\pm 0,5 \mathrm{~cm}$, sedangkan untuk buah naga merah kulit dipisahkan dari daging buhanya lalu dirajang tipis $\pm 0,5 \mathrm{~cm}$. Kemudian dikeringkan dalam oven dengan suhu 50$60^{\circ} \mathrm{C}$ selama 24 jam. Simplisia kering dibersihkan kembali dari kotoran yang 
mungkin tidak hilang pada saat pencucian (sortasi kering). Tahap selanjutnya simplisia kering diblender, disimpan dalam wadah bersih dan tertutup rapat.

\section{Uji Kadar Air}

Penetapan kadar air dilakukan dengan menggunakan alat moisture balance, kerjanya dengan cara menyalakan tombol on/off terlebih dahulu, kemudian piringan diletakan di bagian tengah dan penahan punch di atasnya. Diset program, akurasi maupun temperatur sesuai dengan jumlah simplisia yang diuji. Punch diletakan di atas penyangga, kemudian ditara. Ditimbang serbuk sebanyak $5 \mathrm{~g}$, serbuk simplisia diletakan di atas punch dengan jumlah yang telah disesuaikan. serbuk simplisia diratakan sampai menutupi permukaan punch, lalu ditutup. Setelah proses selesai, maka persen kadar air dari simplisia akan tertera secara otomatis (Mukti, 2012).

\section{Skrining Fitokimia}

Skrining fitokimia untuk senyawa fenolik dilakukan menggunakan $\mathrm{FeCl}_{3}$, flavanoid menggunakan logam mg dan $\mathrm{HCl}$ pekat, saponin dengan pengocokan, terpenoid dan steroid dengan pereaksi libermannburchard. Sedangkan untuk alkaloid dilakukan menggunkan pereaksi mayer (Marjoni, 2016 : Hanani, 2016).

Pembuatan Teh Herbal Campuran Daging Buah Pare (Momordica charantia L.) dan Kulit Buah Naga Merah (Hylocereus lemairei (Hook.) Britton \& Rose)

Tiap formula memiliki berat $2 \mathrm{~g}$, lalu dimasukan dalam wadah kantong teh.
Tabel 1. Komposisi Bahan-Bahan Untuk Formulasi Teh Herbal

\section{Jumlah Bahan yang}

Dicampurkan

\begin{tabular}{ccc} 
Formula & $\begin{array}{c}\text { Daging } \\
\text { Buah } \\
\text { Pare }(\mathbf{g})\end{array}$ & $\begin{array}{c}\text { Kulit buah } \\
\text { naga merah } \\
(\mathbf{g})\end{array}$ \\
\hline FI & 1 & 1 \\
\hline FII & 1,5 & 0,5 \\
\hline FIII & 1,75 & 0,25 \\
\hline FIV & 0,5 & 1,5 \\
\hline FV & 0,25 & 1,75 \\
\hline
\end{tabular}

Uji Aktivitas Antioksidan

a. Pembuatan Larutan DPPH

Kristal DPPH ditimbang sebanyak 2 mg kemudian dilarutkan dalam $2 \mathrm{~mL}$ metanol sehingga dihasilkan konsentrasi 1000 ppm.

\section{b. Persiapan Sampel}

Untuk penyajian tiap formula teh herbal diseduh dengan $150 \mathrm{~mL}$ air panas dan didiamkan selama 5 menit, kemudian teh celup diangkat.

\section{c. Uji Penangkal Radikal DPPH}

Uji aktivitas antioksidan dengan metode DPPH yang digunakan seduhan sampel formula FI, FII, FIII, FIV,FV masingmasing diambil $50 \mu \mathrm{L}$ dimasukkan ke dalam plat $\mathrm{A}$, plat $\mathrm{B}$, plat $\mathrm{C}$, plat $\mathrm{D}$, plat E. Blanko DPPH $50 \mu \mathrm{L}$ metanol (plat G) dan blanko sampel digunakan aquadest $50 \mu \mathrm{L}$ (plat $\mathrm{H}$ ). Plat A sampai plat F dimasukkan DPPH 80 $\mu \mathrm{L} / \mathrm{mL}$ sebanyak $80 \mu \mathrm{L}$. Tutup plat dengan alumunium foil. Campuran diinkubasi selama 30 menit di tempat gelap pada temperatur ruangan. Absorban sampel diukur dengan Microplate reader pada panjang gelombang $520 \mathrm{~nm}$ 
Uji Sifat Organoleptik dengan Metode Hedonik

Uji hedonik terhadap formula terpilih dilakukan terhadap panelis sebanyak 20 orang usia 20-25 tahun diminta mencicipi sampel dan diantara masing-masing pencicipan sampel diharuskan mengonsumsi air minum sebagai penetral, kemudian panelis diminta mengisi kuisioner. Uji organoleptik dilakukan dengan skala hedonik terhadap formula minuman yang memiliki aktivitas antioksidan yang tertinggi, dengan perlakukan penambahan madu $30 \mathrm{~mL}$ dan tanpa penambahan madu.

\section{Analisa Data}

Persen inhibisi dihitung dengan rumus

$$
\begin{aligned}
& \% \text { Inhibisi } \\
& =\frac{\left(A C_{1}-A C_{0}\right)-\left(A S_{1}-A S_{0}\right)}{\left(A C_{1}-A C_{0}\right)} \times 100 \%
\end{aligned}
$$

Kemudian data dianalisa menggunakan One Way Analylis of Variance (ANOVA) dan metode Tukey.

\section{HASIL DAN PEMBAHASAN}

Tujuan dari penelitian ini adalah untuk membuat formulasi teh herbal yang memiliki aktivitas antioksidan yang kuat dan disukai dari campuran buah pare dan kulit buah naga merah yang telah dikeringkan pada suhu $50-60^{\circ} \mathrm{C}$. Buah pare (Momordica charantia L.) merupakan sampel utama dari penelitian ini karena buah pare merupakan tumbuhan daerah tropis yang mudah dibudidayakan dan tidak bergantung musim (Riyadi et al, 2015) serta harganya relatif murah.

Buah naga merah (Hylocereus lemairei (Hook.) Britton \& Rose) adalah buah yang mudah dijumpai dan sering hanya dimanfaatkan daging buahnya untuk dikonsumsi. Pemanfaatan limbah kulit buah naga belum banyak diteliti dan dikembangkan sebagai obat atau sebagai sedian yang meningkatkan daya tahan tubuh. Sedangkan, kulit buah naga masih memiliki kandungan senyawa antioksidan yang cukup tinggi. Penelitian Nuliyana (2010) melaporkan bawah dalam $1 \mathrm{mg} / \mathrm{mL}$ kulit buah naga dapat menghambat sebanyak $83,48 \%$ radikal bebas.

Proses pembuatan simplisia buah pare dan buah naga merah meliputi sortasi basah, pencucian, pengeringan, perajangan dan sortasi kering. Sampel buah pare yang telah kering berwarna hijau kecoklatan dan kulit buah naga merah berwarna merah maron dihaluskan dan kemudian ditentukan kandungan airnya. Kadar air simplisia buah pare diperoleh sebesar 3,06\% dan kulit buah naga merah sebesar $5,42 \%$. Nilai ini menujukan bahwa simplisia yang digunakan memenuhi ketentuan kadar air simplisia buah yaitu <8\% (Anonim, 1985). Kadar air harus ditentukan karena air yang tersisa dalam simplisia merupakan media pertumbuhan kapang dan jasad renik.

Skrining fitokimia simplisia dari buah pare dan kulit buah naga merah dilakukan secara kualitatif dengan menggunkan beberapa pereaksi spesifik yang hasilnya yang dapat dilihat pada tabel 2. Tujuan skrining fitokimia untuk memberikan gambaran tentang golongan senyawa yang terkandung dan memberikan gambaran produk yang dihasilkan akan memberikan aktivitas yang diinginkan. 
Tabel 2. Hasil Uji Kandungan Metabolit Sekunder dari Sampel Segar dan Simplisia Daging Buah Pare (Momordica charantia L.), Kulit Buah Naga Merah (Hylocereus lemairei (Hook.) Britton \& Rose

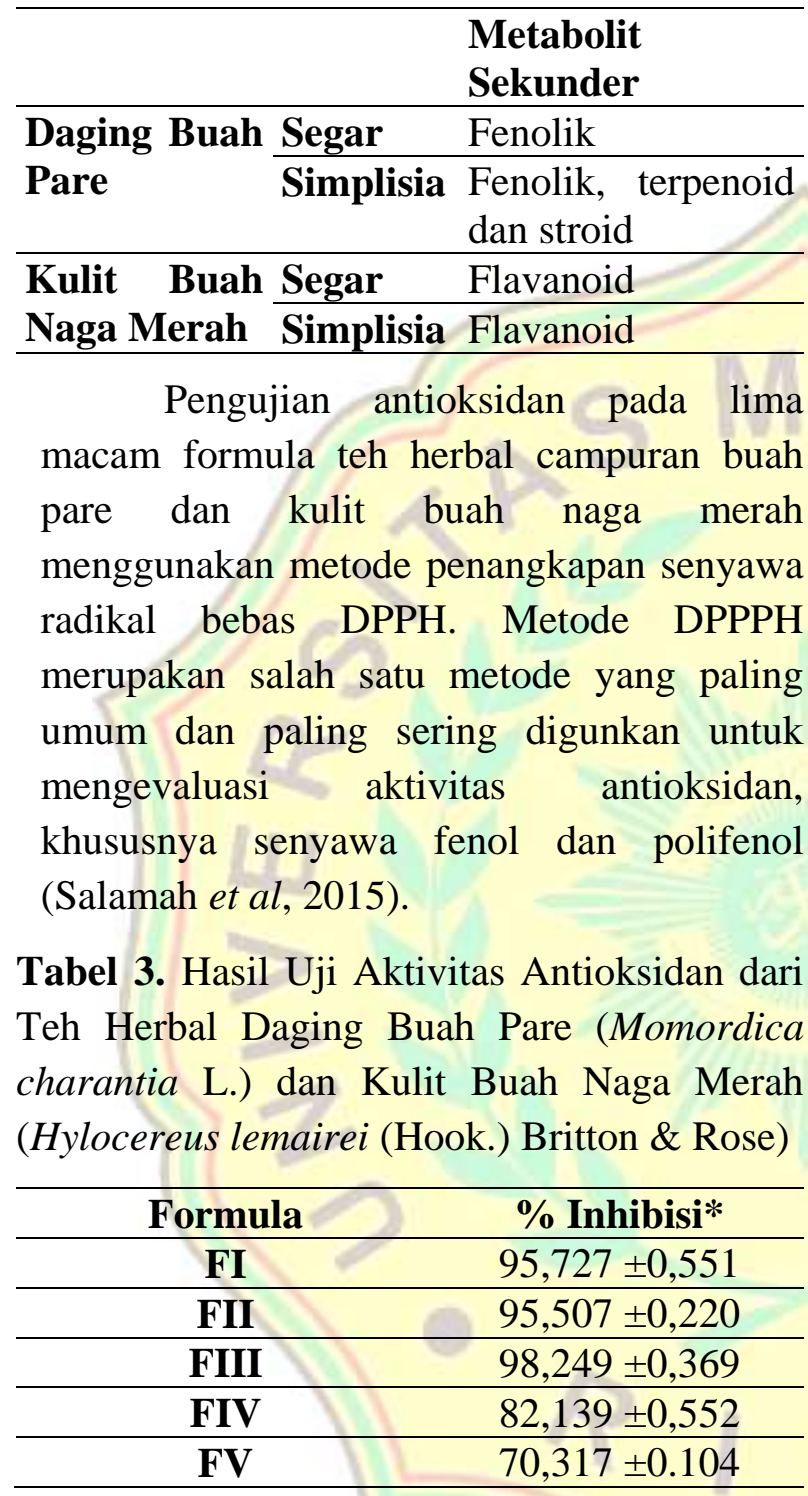

*Replikasi 3 kali pengulangan

Hasil uji aktivitas antioksidan tertinggi dapat dilihat pada Table 3. Persen inhibisi ini dilanjutkan dengan analisis menggunakan one way ANOVA dengan metode Tukey diperoleh hasil formula FIII berbeda sangat nyata $(p<0,01)$ dengan formula FI, formula FII, formula FIV,dan formula FV.

Aktivitas penangkapan radikal bebas DPPH teh celup buah pare dan kulit buah naga mengalami peningkatan seiring dengan berkurangnya komposisi kulit buah naga untuk formula FI dan FII serta menurunya komposisi buah pare dalam formula FIV dan FV. Aktivitas penangkapan radikal bebas DPPH tertinggi terdapat pada perlakuan teh celup formula FIII dimana pada formula ini terdiri dari $1,75 \mathrm{~g}$ serbuk kasar buah pare dan 0,25 g serbuk kasar kulit buah naga merah.

Aktivitas penangkapan radikal bebas DPPH terendah terdapat pada perlakuan teh celup dengan komposisi buah naga yang terbanyak yaitu pada formula FV sebanyak 1,75 g. Hal ini kemungkinan disebabkan karena kandungan antioksidan pada serbuk kasar kulit buah naga merahlebih rendah dari pada serbuk kasar buah pare. Hal ini dikarenakan pada kulit buah naga merah hanya positif mengandung senyawa flavonoid, dan tidak mengandung senyawa fenolik, sedangkan pada serbuk kasar daging buah pare positif mengandung fenolik, terpenoid dan steroid.

Fenolik merupakan senyawa metabolit sekunder yang memiliki aktivitas antioksidan yang kuat. Sehingga hal ini diduga senyawa fenolik pada simplisia daging buah pare lebih memberikan efek antioksidan dari pada senyawa flavanoid pada simplisia kulit buah naga merah. Pada penelitian (Pujimulyani et al, 2010) kadar fenol total kunir putih setelah dilakukan blanching lebih tinggi secara nyata dibanding pada kunir putih segar. Song et al, (2013) juga melaporkan bahwa memasak dengan cara perebusan terhadap jagung manis segar selama 1, 3 dan 5 menit dapat meningkatkan total fenolik. Hal ini diduga terjadi degradasi senyawa fenol komplek menjadi fenol sederhana. Selain itu diduga senyawa fenol tidak mengalami oksidasi enzimatis sehingga jumlahnya tidak turun. 
Betasianin termasuk golongan senyawa flavonoid yang merupakan bagian dari senyawa polifenol yang bersifat antioksidan. Betasianin adalah pigmen yang memberikan warna merah sampai ungu yang merupakan salah satu jenis zat warna betalin yang banyak terdapat pada tumbuhan Caryophyllales dan Cactaceae. Kulit buah naga merah merupakan salah satu famili Cactaceae yang memiliki senyawa betasianin. Faktor tersebutlah yang mungkin mempengaruhi formula teh herbal yang didominasi kulit buah naga merah memiliki aktivitas antioksidan rendah. Aktivitas antioksidan dipengaruhi oleh jumlah senyawa betasianin yang terkandung dalam bahan, semakin banyak senyawa betasianin yang terdapat dalam bahan maka aktivitas antioksidannya akan semakin meningkat, begitu pula sebaliknya apabila senyawa betasianin yang terdapat dalam bahan maka aktivitas antioksidannya akan semakin menurun pula (Shofiati et al, 2014). Selain itu, stabilitas betasianin dipengaruhi oleh suhu pengeringan, suhu penyimpanan, $\mathrm{pH}$, cahaya dan oksidator (Khulud et al, 2007 ; Rengku et al, 2017).

Formula yang memiliki aktivitas antioksidan yang tertinggi dilanjutkan pada pengujian sifat organoleptik. Uji organoleptik pada penelitian ini digunakan metode afektif.

Metode afektif merupakan metodeankag digunakan untuk mengukur sikap subjektif konsumen terhadap produk berdasarkan sifatsifat organoleptik (Anonim, 2006). Adapun uji yang dipilih pada metode afektif adalah uji hedonik.

Uji hedonik merupakan pengujian yang paling banyak digunakan untuk mengukur tingkat kesukaan terhadap produk. Uji hedonik dilakukan terhadap formula teh herbal yang memiliki aktivitas antioksidan yang tertinggi yang diberikan perlakukan dengan tanpa madu dan dengan penambahan madu sebanyak $30 \mathrm{~mL}$. Penambahan madu sebanyak $30 \mathrm{~mL}$ berdasarkan uji organoleptik yang disukai penelis pada produk minuman herbal dari buah pare yang dilakukan oleh Lestari (2016), selain itu madu juga memiliki rasa manis, nilai gizinya tinggi dan sangat berkhasiat untuk mengobati berbagai penyakit.

Uji hedonik ini menggunkan panelis sebanyak 20 orang dengan rentang usia 2025 tahun. Rentang usia ini dipilih berdasarkan tujuan dan manfaat dari teh herbal ini yaitu sebagai minuman pencegahan diusia dini sehingga dapat mengurangi resiko terjadinya penyakit degeneratif akibat paparan radikal bebas (Lestari, 2016). Hasil uji hedonik dari 20 panelis terhadap teh herbal dari formula terpilih yaitu formula FIII dengan perlakuan dengan madu dan tanpa madu.

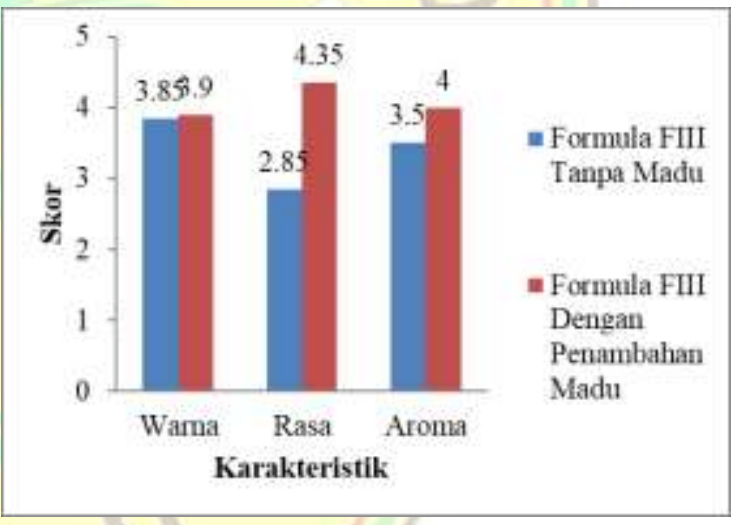

1. Diagram Batang Uji Hedonik Teh Herbal Daging Buah Pare (Momordica charantia L.) dan Kulit Buah Naga Merah (Hylocereus lemairei (Hook.) Britton \& Rose)

Skor penilaian masing-masing panelis terhadap warna, rasa dan aroma untuk formula dengan madu dan tanpa madu dapat dilihat pada Gambar 1. Adapun warna produk FIII tanpa madu adalah kuning kecoklatan. Sedangkan untuk FIII dengan penambahan madu adalah coklat kehitaman, hal ini disebabkan karena warna dari madu 
yang coklat pekat kehitaman. Karakteristik rasa pada produk FIII dengan penambahan madu memiliki rasa manis. Rasa manis pada madu ini dihasilkan dari nektar yang dihisap lebah madu. Nektar merupakan senyawa komplek yang dihasilkan oleh kelenjar necteriffiper dalam bunga dan berbentuk larutan gula dengan konsentrasi bervariasi (Suranto, 2004). Sedangkan untuk produk FIII tanpa madu meliliki rasa kelat dan meninggalkan rasa sedikit pahit diakhirnya. Karakteristik aroma untuk produk FIII dengan penambahan madu memiliki aroma manis yang khas dari penambahan madu. Sedangkan untuk aroma pada produk FIII tanpa penambahan madu memiliki aroma segar dari simplia buah pare dan kulit buah naga merah.

\section{KESIMPULAN}

Formula teh herbal FIII dengan komposisi $1,75 \mathrm{~g}$ serbuk kasar daging buah pare (Momordica charantia L.) dan 0,25 g serbuk kasar kulit buah naga merah (Hylocereus lemairei (Hook.) Britton \& Rose) merupakan formula terbaik yang memberikan aktivitas antioksidan sebesar $98,249 \%$, serta analisis one way ANOVA metode Tukey diperoleh persen inhibisi yang berbeda sangat nyata $(p<0,01)$ dari 4 formula teh herbal lainnya. Untuk uji karakteristik hedonik terhadap warna, rasa dan aroma tertinggi setelah formula FIII ditambahkan madu sebanyak $30 \mathrm{~mL}$ dengan kategori suka.

\section{DAFTAR PUSTAKA}

Anonim, 1985, Cara Pembuatan Simlisia, Departemen Kesehatan RI, Jakarta, Hal 6-10.

Anonim, 2006, Pengujian Organoleptik (Evaluasi Sensori) dalam Industri Pangan, Ebook Pangan, Hal 2-7.
Choo, W., S., 2011, Antioxidan Properties of Two Species of Hylocereus Fruit, Advances in Applied Research, 2 : 418-425.

Emil, S, 2011, Untung Berlipat Dari Bisnis Buah Naga Unggul, Lily Publisher, Yogyakarta, Hal 16-23.

Hamissou, M., Smith, A., C., Robert E. Carter Jr and Jimmy K., 2013, Antioxidative properties of bitter gourd (Momordica charantia) and zucchini (Cucurbita pepo), J. Food Agric, 25 (9) : 641-647.

Hanani, E., 2016, Analisa Fitokimia, EGC, Jakarta, Hal 69-114.

Islam, S., Jalaluddin, M., Hettiarachchy N., S., 2011, Bioactive compounds of bitter melon genotypes (Momordica charantia L.) in relation to their physiological functions, Functional Foods in Heals and Disease, 2 : 6174.

Khulud, A., D., Widjanarko, S., B., Murtini, E., S., 2007, Ekstraksi dan Stabilitas Betasianin Daun Darah (Alternanthera Dentata) (Kajian Perbandingan Pelarut Air:Etanol dan Suhu Ekstraksi), Jurnal Teknologi Pertanian, 8 (3) : 172-181.

Lestari, S., A., I., 2016, Uji Aktivitas Antioksidan Minuman Herbal Buah Pare (Momordica charanti L.), Kulit Buah Naga Merah (Hylocereus polyrhizus) dengan Penambahan Madu, Skripsi Sarjana Farmasi, STIFAR, Pekanbaru.

Marjoni, R., 2016, Dasar-Dasar Fitokimia Untuk Diploma III Farmasi, CV Trans Info Media, Hal 7-13.

Mukti, D., 2012, Uji Efektivitas Antibakteri Ekstrak Etanol Buah Pare 
(Momordica charantia L.) Terhadap Streptococcus mutans Penyebab Karies Gigi, Skripsi, Fakultas Matematika dan Ilmu Pengetahuan Alam Universitas Pakuan, Bogor.

Nurliyana, R., Syed Z., I., Mustapha S., K., Aisyah, M., R., Kamarul R., K., 2010, Antioxidant study of pulps and peels of dragon fruits : a comparative study, International Food Research Journal, 17 : 367-375.

Pujimulyani, D., Raharjo, S., Marsono, Y., Santoso, U., 2010, Aktivitas Antioksidan dan Kadar Senyawa Fenolik pada Kunir Putih (Curcuma mangga Val.) Segar dan Setelah Blanching, Agritech, 30 (2) : 68-74.

Ravikumar, C., 2014, Review on Herbal Teas, J. Pharm. Sci. \& Res, 6 : 236238.

Rengku, P., M., Ridhay, A., Prismawiryanti, 2017, Ekstraksi dan Uji Stabilitas Betasianin dalam Ekstrak Buah Kaktus (Opuntia elatior Mill.), Jurnal Riset Kimia, 3 (2) : 142-149.

Riyadi, N., H., Ishartani, D., Purbasari R., 2015, Mengangkat Potensi Pare (Momordica Charantia) Menjadi Produk Pangan Olahan sebagai Upaya Diversifikasi, Pros Sem Nas
Masy Biodiv Indon, 1 (5) : 11671172.

Salamah, N., Widyaningsih, W., Izati, I., Susanti, H., 2015, Aktivitas penangkapan Radikal Bebas Ekstrak Etanol Ganggang Hijau Spirogyra sp. dan Ulva lactuca dengan Metode DPPH, Jurnal Ilmu Kefarmasian Indonesia, 13 (2) : 145-150.

Shofiati, A., Andriani, M,. A., M., Anam, C., 2014, Kajian Kapasitas Antioksidan dan Penerimaan Sensoris Teh Celup Kulit Buah Naga (Pitaya Fruit) dengan Penambahan Kulit Jeruk Lemon dan Stevia, Jurnal Teknosains Pangan, 3 (2) : 5-12.

Song, J., F., Liu C.,Q., Li D., J ., Meng L., L., 2013, Effect of Cooking Methods on Total Phenolic and Carotenoid Amounts and DPPH Radical Scavenging Activity Of Fresh and Frozen Sweet Corn (Zea mays) Kernels, Czech, J. Food Sci., 31 (6) : 607-612.

Suranto, A., 2004, Khasiat dan Manfaat Madu Herbal, Agromedia Pustaka, Tangerang.

Wisam, A., 2007, Manfaat dan Budidaya Pare, Sinar Cemerlang Abadi, Jakarta, Hal 1-18. 